Received 00th January 20xx, Accepted 00th January 20xx DOI: $10.1039 / x 0 \times x 00000 x$

\title{
Continuous flow synthesis of menthol through the tandem cyclisation-hydrogenation of citronellal catalysed by scrap catalytic converters
}

\author{
Alessio Zuliani, ${ }^{a}$ Camilla Maria Cova, ${ }^{a}$ Roberta Manno, ${ }^{b}$ Victor Sebastian, ${ }^{b, c, d}$ Antonio A. Romero ${ }^{a}$ and \\ Rafael Luque*a,e
}

\begin{abstract}
A continuous flow synthesis of menthol starting from citronellal catalysed by scrap catalytic converters is reported. The reaction was conducted in a tandem system connecting in series two catalytic systems, the first having Lewis acid properties (favouring the cyclisation of citronellal to isopulegols) and the second having hydrogenation catalytic activity (catalysing the hydrogenation of isopulegols to menthols). A Lewis acid catalyst was prepared by supporting iron oxide nanoparticles over a waste material, i.e. the ceramic core of scrap catalytic converters (SCATs) via a microwave assisted method. Most importantly, SCATs, containing low residual noble metals content, could be directly employed in the second step as hydrogenation catalyst. The reaction was performed studying the influence on the yield and selectivity to (-)-menthol of various reaction parameters ( $\mathrm{T}, \mathrm{p}$ and flow rate). Operating with the best reaction conditions (at $0.1 \mathrm{~mL} \mathrm{~min}{ }^{-1}$ flow rate and at $373 \mathrm{~K}$ and $413 \mathrm{~K}$ for cyclisation and hydrogenation steps respectively) a conversion of $>99 \%$ of (+)-citronellal with $77 \%$ final yield to (-)-menthol was obtained.
\end{abstract}

\section{Introduction}

(-)-menthol (Fig.1) is one of the most produced solid-flavour compound with a worldwide demand of more than 30.000 metric tons per year. ${ }^{1,2}$

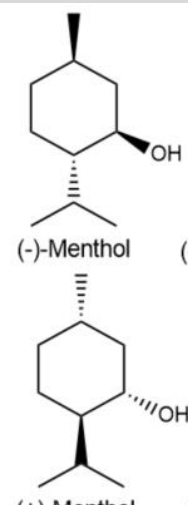

(+)-Menthol

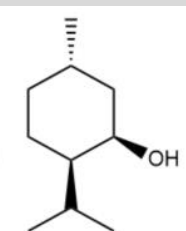

(-)-NeoMenthol

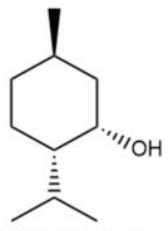

(+)-NeoMenthol
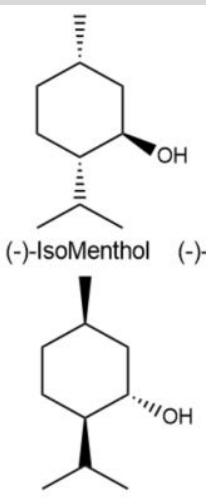

(+)-IsoMenthol (+)-NeolsoMenthol
Fig.1 Structure of (-)-menthol and its isomers.

a. Departamento de Quımica Organica, Universidad de Cordoba, Edificio MarieCurie (C-3), Ctra Nnal IV-A, Km 396, Cordoba, Spain.E-mail: rafael.luque@uco.es

b. Nanoscience Institute of Aragon and Chemical and Environmental Engineering

Department, University of Zaragoza, Pedro Cerbuna 12, 50009, Zaragoza, Spain

c. Networking Research Center CIBER-BBN, 28029, Madrid, Spain.

d. Aragón Materials Science Institute, ICMA, CSIC, University of Zaragoza, Pedro Cerbuna 12, 50009, Zaragoza, Spain.

e. Peoples Friendship University of Russia (RUDN University), 6 Miklukho Maklaya str., 117198, Moscow, Russia.

Electronic Supplementary Information (ESI) available: details of the continuous flow tandem systems and additional experimental data. See DOI: 10.1039/x0xx00000x
Its interaction with human receptors confers a fresh taste and a cooling effect to a large variety of products ranging from oral hygiene, drugs and tobacco to confectionary, cosmetics and foodstuffs. ${ }^{3-5}$ Moreover, (-)-menthol has been proved to be an analgesic substance, potentially expanding its market to drugs. ${ }^{6,7}$

Remarkably, the commonly used term "menthols" refers to the group of eight stereoisomeric forms: menthol, neomenthol, isomenthol and neoisomenthol, represented in Fig.1.2,8 However, (-)-menthol has enhanced cooling and tasting properties, being the most valuable isomer. ${ }^{9,10}$ Despite (-)-menthol is primarily extracted from natural oils, typically of Mentha piperita and Mentha arvensis, alternative synthetic routes have been developed in order to stabilise the market fluctuations resulting from unpredictable bad harvests. ${ }^{11}$

Main industrial processes include the Symrise process (known as Haarmann \& Reimer process) and the Takasago process.

In the Symrise process, thymol is hydrogenated to menthols (therefore the all diastereomers isomenthol, neomenthol, neoisomenthol and menthol) and sequentially (-)-menthol is recovered by distillation and crystallization. In the Takasago process (Scheme 1A), myrcene is transformed into $(+)$-citronellal, which is sequentially cyclised and hydrogenated to (-)-menthol. ${ }^{12}$

Similarly to Takasago process, in 2012, BASF started a new plant where (-)-menthol is synthesized from (+)-citronellal derived from the upgrading of citral oils (e.g. by the enantioselective hydrogenation of geraniol and nerol). ${ }^{13}$ The cyclisation of citronellal to isopulegols is normally carried out using zinc bromide or tris(2,6-diarylphenoxy)aluminium as catalysts. ${ }^{14}$ 


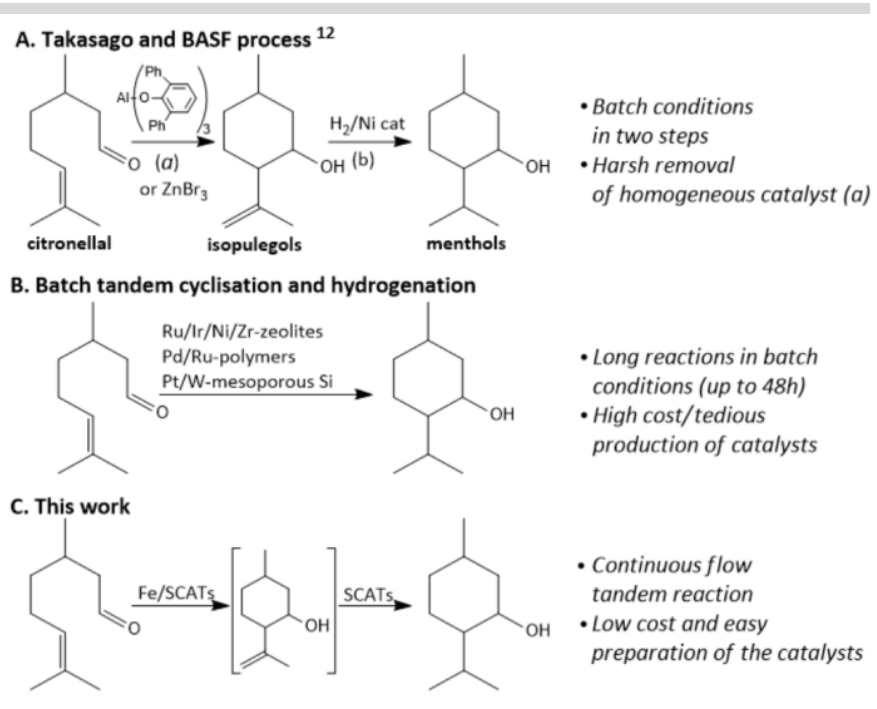

Scheme 1 Synthetic strategies for the sequential cyclisation and hydrogenation of citronellal.

However, the homogeneous nature of the catalysts and the corrosion issues derived from the utilisation of bromide salts has driven research in the field to investigate heterogeneous systems. ${ }^{15-18}$ These systems have been further explored in order to design bi-functional catalysts having Lewis-acid and hydrogenating properties for the one-step synthesis of (-)-menthol starting from (+)-citronellal. ${ }^{19-23}$

For example, Ru supported over zeolites (H-BEA) has been recently reported as effective catalytic system for menthols production (up to $87 \%$ operating at $372 \mathrm{~K}$ under 25 bar $\mathrm{H}_{2}$ pressure in 1 h). ${ }^{24}$ Oldani et al. employed $\mathrm{Pd}$ and $\mathrm{Ru}$ nanoparticles supported over perfluorinated superacid polymers obtaining $99 \%$ yield to $(-)$-menthol at $353 \mathrm{~K}$ under 10 bar $\mathrm{H}_{2}$ pressure after $23 \mathrm{~h}$ of reaction using water as solvent. ${ }^{25}$ More recently, Pt/W bifunctional catalysts supported over mesoporous silica (TUD-1) have led to $96 \%$ yield to menthols operating at $353 \mathrm{~K}$ for $16 \mathrm{~h}$ under $20 \mathrm{bar}_{2}$ pressure. ${ }^{26}$ Despite these interesting results, the proposed synthetic strategies still entail a number of practical limitations, mainly due to the conventional batch conditions, long times of reaction and the utilisation of expensive-containing noble metals and/or sophisticated catalytic systems (Scheme 1B).

Herein, an alternatively simple and efficient approach for the selective synthesis of $(-)$-menthol starting from $(+)$-citronella performed under continuous flow (tandem) conditions catalysed by waste-derived catalysts was explored (Scheme 1C). Under optimum reaction conditions, a maximum of $92 \%$ yield to menthols ( $84 \%$ selectivity to (-)-menthol) could be achieved. To the best of our knowledge, no reports on a similar approach have been reported in literature up to today. Flow conditions were selected as safe and controllable alternative to batch synthesis. ${ }^{27,28}$ In addition, flow chemistry has been reported as one of the "Top Ten Emerging Technologies" with the potential to turn the planet more sustainable. ${ }^{29}$ In order to maximize each step of the reaction, avoiding the formation of side products, flow conditions were carefully designed and controlled stepwise in a tandem protocol by connecting in series two cartridges, one containing a Lewis acid catalyst (designed for the cyclisation of citronellal) and one containing an hydrogenation catalyst (for the sequential hydrogenation of isopulegols). The continuous flow apparatus was set up by linking an $\mathrm{H}-\mathrm{Cube}{ }^{\circledR}$ Mini Plus (Thalesnano Inc.) to an X-Cube ${ }^{\mathrm{TM}}$ (Thalesnano Inc.). The apparatus allowed to individually control the temperature of each cartridge.

The Lewis acid catalyst was prepared by supporting iron over a cheap waste material, i.e. the ceramic core of scrap automotive catalytic converters (denoted as "SCATs") to obtain iron oxide nanoparticles. SCATs were selected due both to low cost (and availability) and to the presence of noble metal nanoparticles $(<0.5 w t . \%) .{ }^{30}$ Furthermore, the direct applicability of SCATs in catalysis have been previously demonstrated in simple batch experiments. ${ }^{31-33}$

\section{Experimental Sections}

Iron (II) chloride tetrahydrate $\left(\mathrm{FeCl}_{2} \cdot 4 \mathrm{H}_{2} \mathrm{O}, 99.99 \%\right.$ trace metals basis), iron (III) chloride hexahydrate $\left(\mathrm{FeCl}_{3} \cdot 6 \mathrm{H}_{2} \mathrm{O}, 99.99 \%\right.$ trace metals basis), toluene ( $\geq 99.8 \%)$, acetone $(\geq 99.5 \%)$, sodium hydroxide $(\mathrm{NaOH}, \geq 98 \%)$, ( \pm )-citronellal $(\geq 95 \%)$, (+)-citronellal (>96\%), octane (98\%), (-)-isopulegol ( $\geq 99 \%$, enantiomeric ratio: $\geq 99.5: 0.5$ ), (-)-menthol ( $\geq 99 \%$, enantiomeric ratio: $\geq 99.5: 0.5$ ), silica, and ethanol ( $\geq 98 \%$ ) were purchased from Sigma-Aldrich Inc., St. Louis, MO, USA. All reagents were used without any further purification. Scrap ceramic-cores of automotive catalytic converters (SCATs) were collected from Provaluta España Reciclaje de Metales, S.L., Córdoba (ES). SCATs were previously smashed in Provaluta S.L. via a grinding process and provided in the form of powders.

\subsection{Set up of the Tandem apparatus}

The tandem apparatus was set up by linking an $\mathrm{H}-\mathrm{Cube}{ }^{\circledR}$ Mini Plus (Thalesnano Inc.) to an X-Cube ${ }^{\mathrm{TM}}$ (Thalesnano Inc.), as illustrated in Fig. 2. More in details, the outcome connector of the cartridge of the $\mathrm{H}-\mathrm{Cube}^{\circledR}$ (Cartridge 1 ) was connected with the income of the cartridge of the X-Cube (Cartridge 2). The outcome of the cartridge of the X-Cube was connected to the pressure valve of the $\mathrm{H}-\mathrm{Cube}^{\circledR}$. More details can be found in the Fig.S1 of the ESI.

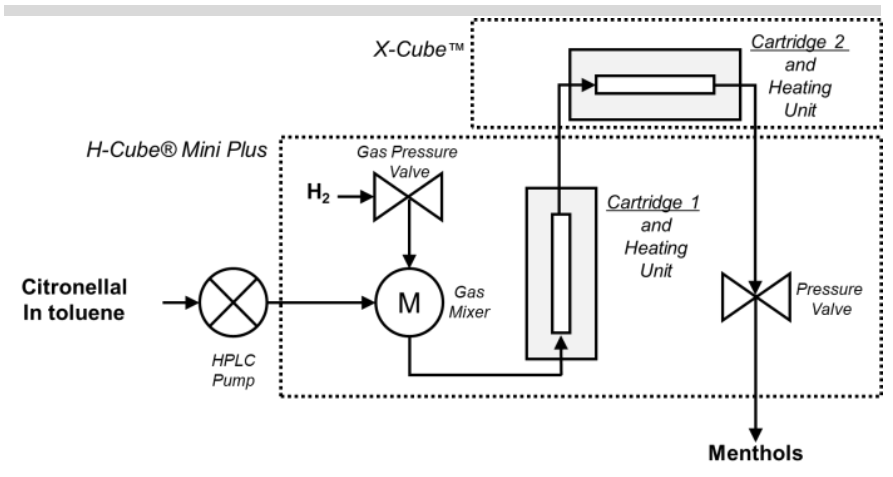

Fig.2 Diagram of the set-up for the continuous flow synthesis of menthols from citronellal. 


\subsection{General procedure for synthesis of the catalysts}

Before utilisation, SCATs were washed and dried in order to remove the superficial carbonaceous residuals and all other pollutant residues. More in details, $50 \mathrm{~g}$ of SCATs were dispersed in $100 \mathrm{~mL}$ of distilled water and ethanol (1:1). Sequentially, the mixture was ultrasonicated in a US bath for 2 $h$ (due to US thermal effects, the temperature measured $\sim 323$ K). Finally, the sonicated SCATs were filtrated on a vacuum filter, washed several times with water, acetone and ethanol and dried in a $373 \mathrm{~K}$ oven for $12 \mathrm{~h}$.

A sequence of $\mathrm{Fe} / \mathrm{SCATs}$ catalysts was prepared varying the $\%_{\mathrm{wt}}$ of Fe adapting a microwave-assisted synthesis developed by Moores et al. ${ }^{34}$ More in details, a fixed amount of washed SCATs $(1.15 \mathrm{~g})$ was added to $20 \mathrm{~mL}$ of a previously stirred (10') homogeneous aqueous solution of $\mathrm{FeCl}_{2} \cdot 4 \mathrm{H}_{2} \mathrm{O}, \mathrm{FeCl}_{3} \cdot 6 \mathrm{H}_{2} \mathrm{O}$ and $4.7 \mathrm{~mL}$ of a solution 1.25 $\mathrm{M}$ of $\mathrm{NaOH}$. Three samples (called A, B and $C$ ) were produced varying the quantities of the iron precursors, as reported in Table 1.

Table 1 Quantities of Fe precursors for the theoretical x\% ${ }_{w t} F e / S C A T s$.

\begin{tabular}{cccc}
\hline Sample & Theoretical $x \%{ }_{w t} F e$ & $\mathrm{FeCl}_{2} \cdot 4 \mathrm{H}_{2} \mathrm{O} / \mathrm{mg}$ & $\mathrm{FeCl}_{3} \cdot 6 \mathrm{H}_{2} \mathrm{O} / \mathrm{mg}$ \\
\hline $\mathrm{A}$ & $12 \%$ & 188 & 510 \\
$\mathrm{~B}$ & $6 \%$ & 94 & 255 \\
C & $3 \%$ & 47 & 127 \\
\hline
\end{tabular}

Sequentially, the mixture was heated in a MW-oven (Ethos Microwave, Milestone Srl) at $383 \mathrm{~K}$ for $1 \mathrm{~h}$ (5' ramp). The resulting material was filtrated, washed several times with water and ethanol, and dried in a $373 \mathrm{~K}$ oven for $12 \mathrm{~h}$.

Following the same procedure, three additional samples of $\mathrm{Fe} / \mathrm{SiO}_{2}$ were prepared with the quantities of iron precursor reported in Table 2 (having the same theoretical 12\%wt iron content of sample A, the most active Fe/SCATs, as explained in following section 3.2 ).

Table 2 Quantities of Fe precursors for the theoretical $12 \%_{\mathrm{wt}} \mathrm{Fe} / \mathrm{SiO}_{2}$.

\begin{tabular}{cccc}
\hline Sample & Theoretical $\times \%_{w t} \mathrm{Fe}$ & $\mathrm{FeCl}_{2} \cdot 4 \mathrm{H}_{2} \mathrm{O} / \mathrm{mg}$ & $\mathrm{FeCl}_{3} \cdot 6 \mathrm{H}_{2} \mathrm{O} / \mathrm{mg}$ \\
\hline $\mathrm{D}$ & $12 \%$ & 188 & 510 \\
$\mathrm{E}$ & $12 \%$ & 556 & $/$ \\
$\mathrm{F}$ & $12 \%$ & $/$ & 270 \\
\hline
\end{tabular}

\subsection{Preparation of the cartridges}

In order to perform the continuous flow tests, washed SCATs, $\mathrm{Fe} / \mathrm{SCATs}$ or $\mathrm{Fe} / \mathrm{SiO}_{2}$ were charged in stainless steel cartridges sealed on both sides with sealings systems, made of graphite filled PTFE sealing rings, stainless steel filters and PTFE membranes (CatCatrs ${ }^{\circledR}$ Thalesnano Inc.). Two different types of cartriges were employed: $30 \mathrm{~mm}$ and $70 \mathrm{~mm}$-long ThalesNano CatCarts $^{\circ}$. The cartridges were filled with $150 \mathrm{mg}$ and $450 \mathrm{mg}$ of catalysts respectively. Prior to utilisation, the filled cartridges were washed in the flow apparatus at 30 bar liquid pressure with toluene at $373 \mathrm{~K}$ for $30^{\prime}$ at $8 \mathrm{~mL} \mathrm{~min}^{-1}$ flow rate, in order to remove all the eventual residues and all iron nanoparticles not fixed/slightly fixed on the SCATs. After the washing cycles, fresh fluxed toluene was analysed by GC and ICP-MS analysis in order to confirm the cleanliness of the system and that no leaching of the catalysts occurred.

\subsection{Catalysts characterization}

Powder X-ray diffraction (XRD) patterns were recorded with a Bruker D8 DISCOVER A25 diffractometer (PanAnalytic/Philips, Lelyweg) using CuKa ( $\lambda=1.5418 \AA \AA$ ) radiation. The patterns were collected over a $2 \theta$ ranging from $10^{\circ}$ to $80^{\circ}$ with a step size of $0.018^{\circ}$ and counting time of $5 \mathrm{~s}$ per step.

The metallic composition of the catalysts was determined by Microwave Plasma Atomic Emission Spectroscopy (MP-AES) (Agilent 4100 MP-AES). The analysis were carried out by digesting $20 \mathrm{mg}$ of the selected catalyst with $5 \mathrm{~mL}$ of nitric acid $\left(\mathrm{HNO}_{3}\right)$ and hydrochloric acid $(\mathrm{HCl})$ in a volume ratio of $1: 3$ at $473 \mathrm{~K}$ for $20^{\prime}$ in a microwave oven (Milestone Ethos Plus, Milestone $\mathrm{Srl}$ ). Before analysis, the digested sample was filtrated with hydrophilic syringe filters $(0.2 \mu \mathrm{m})$ in order to discard any fragmented particles and dilueted with Milli-Q water to a final volume of $30 \mathrm{~mL}$.

The aberration corrected Scanning Transmission Electron Microscopy (Cs-corrected STEM) images were adquired in a FEI XFEG TITAN electron microscope operating at $300 \mathrm{kV}$ and equipped with a CETCOR Cs-probe corrector (CEOS Company), allowing the formation of an electron probe of $0.08 \mathrm{~nm}$. The samples were prepared by US dispersion in ethanol and by pipetting $10 \mu \mathrm{L}$ of the obtained suspension onto a TEM copper grid having a continuous carbon film. After complete evaporation of the solution, the samples were analysed by Highangle annular dark-field scanning transmission electron microscopy (STEM-HAADF).

Elemental analysis were performed with an EDS (EDAX) detector which allows performing EDS experiments in the scanning mode. The analysis were conducted at the Laboratory of Advanced Microscopies, LMA-INA-University of Zaragoza. Z-contrast (achieved by the HAADF detector) was employed in order to enable an image contrast based on the atomic number. $X$-ray photoelectron spectroscopy (XPS) analysis were performed with an Axis Ultra DLD spectrometer (Kratos Tech). In order to perform the anlysis, the samples were mounted on a sample rod placed in the pretreatment chamber of the spectrometer and sequentially evacuated at room temperature. The spectra were excited by a monochromatized AlK $\alpha$ source at $1486.6 \mathrm{eV}$ and subsequently ran at $12 \mathrm{kV}$ and $10 \mathrm{~mA}$. Survey spectra were measured at $160 \mathrm{eV}$ pass energy and for the individual peak regions, the spectra were recorded with a pass energy of $20 \mathrm{eV}$. The analysis of the peaks were performed with the CasaXPS software using a weighted sum of Lorentzian and Gaussian component curves after Shirley background subtraction. The binding energies were referenced to the internal C1s standard at $284.9 \mathrm{eV}$.

\subsection{Catalytic experiments}

The catalytic tests were performed in the continuous apparatus described previously. Before starting the reaction, the system was rinsed with a solution $20 \mathrm{mM}$ of (+)-citronellal (or $20 \mathrm{mM}$ of 
( \pm )-citronellal or $20 \mathrm{mM}$ of (-)-isopulegol) and $20 \mathrm{mM}$ octane (internal standard) in toluene at $1 \mathrm{~mL} \mathrm{~min}^{-1}$ flow rate for $20^{\prime}$. GC analysis of the outline solution confirmed the cleanliness of the system. Sequentially, the reaction conditions were setted. The $\mathrm{H}_{2}$ was generated by in situ water electrolysis in the $\mathrm{H}$-Cube ${ }^{\circ}$ equipment. The reactions were perfomerd for $2 \mathrm{~h}$, collecting samples every 15' for further analysis. The data were reported after reaching stationary state conditions. Time " 0 " was set up as the first outcome under operative reaction conditions passed through the apparatus.

The conversion and selectivity were determined by gas chromatography (GC) in an Agilent $6890 \mathrm{~N}$ gas chromatograph (60 $\mathrm{mL} \mathrm{min}^{-1} \mathrm{~N}_{2}$ carrier flow, 1.38 bar (20 psi) column top head pressure) using a flame ionization detector (FID). A Restek $\mathrm{Rt}^{\oplus}$-yDEXsa chiral capillary coloumn (30 $\left.\mathrm{m} \times 0.25 \mathrm{~mm} \times 0.25 \mu \mathrm{m}\right)$ was employed. The calibration curve was obtained using octane as internal standard. Standard solutions of $(+)$-citronellal, (-)-isopulegol and (-)-menthol (from 5 to $20 \mathrm{mM}$ ) and $20 \mathrm{mM}$ octane in toluene were analysed by GC to give linear regressions $\left(R^{2}>0.999\right)$. Gas chromatography-mass spectroscopy (GC-MS) analysis were also performed using an Agilent 7820A GC/5977B High Efficiency Source (HES) MSD, in order to identify the obtained products in comparison with commercial standards. The optical rotation was measured using a Zuzi Polarimeter (Model 412 ), at $20^{\circ} \mathrm{C}$ and at $589.44 \mathrm{~nm}$ wavelenght irradiation.

\section{Results and discussion}

\subsection{Characterization of the catalysts}

The structure of the SCATs was reported to be composed of a sequence of coats, made of alumina, silica, titania and ceria ${ }^{35}$ and offers the possibility to support metal nanoparticles, as demonstrated in a recent work. ${ }^{36}$ Iron oxide nanoparticles were then supported on SCATs adapting the microwave-assisted methodology previously described. ${ }^{34}$ Washed SCATs (Cartridge 2 in Figure 2B) were directly employed as catalyst for the hydrogenation step, in order to exploit the presence of trace quantities of noble metals in the matrix, potentially highly active for hydrogenation reactions. ${ }^{37,38}$

In order to evaluate the leaching effects as well as changing in the oxidation states of the metals or morphology variations, STEM-HAADF, MP-AES (in order to check the metal content as well as metal leaching), XPS and XRD analysis were performed both before and after the utilisation of the catalysts.

The elemental compositions of SCATs and Fe/SCATs were analysed by ICP-MS (Inductively Coupled Plasma Mass Spectrometry) and MP-AES (Microwave Plasma Atomic Emission Spectroscopy). Al, $\mathrm{Si}$ and $\mathrm{Mg}$ as well as $\mathrm{Ce}, \mathrm{Fe}$ and traces of $\mathrm{Pt}(<0.2 \mathrm{wt} . \%)$ were detected in the SCATs matrix. On the other hand, the three samples of Fe/SCATs catalyst contained 7.5, 3.4 and $1.8 \%_{\mathrm{wt}}$ Fe (for a detailed list of elemental analysis, please see ESI). Remarkably, the supporting of iron nanoparticles on SCATs was achieved with an important loss of iron of $\sim 40-50 \%_{\text {wt }}$ during the preparation phase, in accordance with the published procedure. ${ }^{34}$ After preliminary studies, described below, sample $7.5 \%$ wt Fe/SCATs was selected as best one, and the article will refer to it as "Fe/SCATs" from now on. No leaching of the employed catalysts was detected by ICP-MS and MP-AES analysis after utilisation.

As shown in XRD patterns in Fig.3, some diffraction lines corresponding to silica, one of the major components of catalytic converter, were observed in both SCATs and Fe/SCATs before and after utilisation.

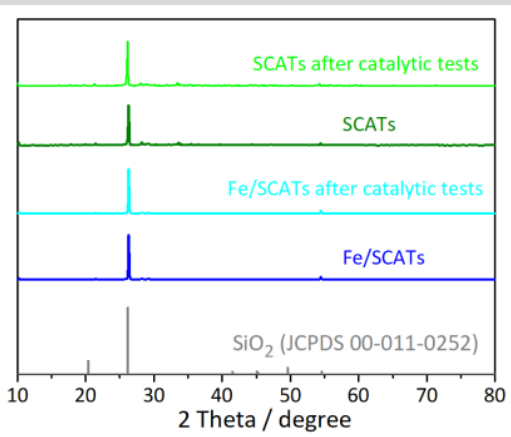

Fig.3 XRD patterns for SCATs and Fe/SCATs.

More in details, the most intense peaks of Fe/SCATs and SCATs

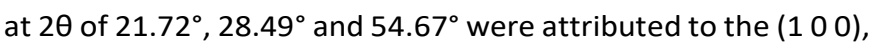
$\left(\begin{array}{lll}0 & 1 & 1\end{array}\right),\left(\begin{array}{lll}2 & 0 & 2\end{array}\right)$ planes of $\mathrm{SiO}_{2}$ with hexagonal structure (JCPDS 00-011-0252). ${ }^{39}$ No specific peaks assignable to iron oxides were clearly observed in the XRD patterns of Fe/SCATs. Also, no relevant changes in the XRD patterns before and after utilisation of the catalysts were detected.

High-angle annular dark-field scanning transmission electron microscopy (STEM-HAADF) and Energy-dispersive X-ray Spectroscopy (EDS) of SCATs and Fe/SCATs materials were subsequently conducted to elucidate the location of metal (oxide) nanoparticles. As depicted in Fig.4-A and Fig.4-B (SCATs), the presence of laminar smashed structures of silica and alumina derived from the honeycomb structure of the catalytic converter could be observed.
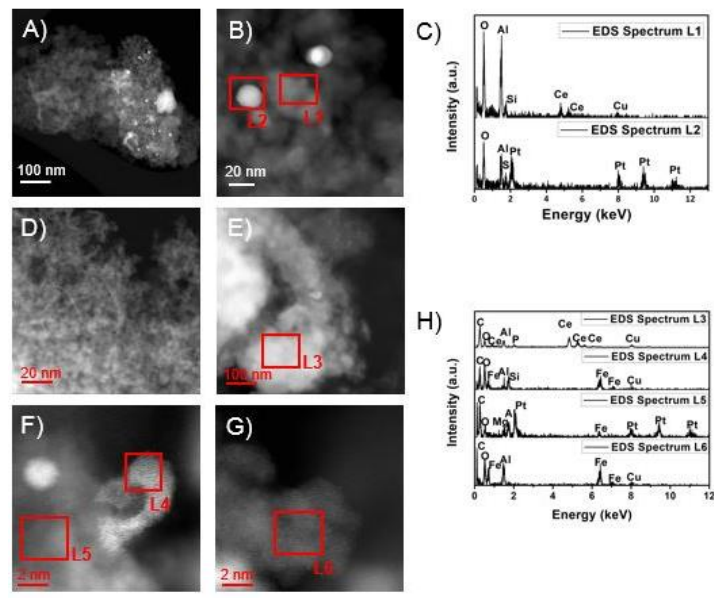

Fig.4 (A) and (B) STEM-HAADF images of SCATs. (C) EDS analysis of selected locations (L1 and L2) of SCATs. (D), (E), (F) and (G) STEM-HAADF images of Fe/SCATs. (H) EDS analysis of selected locations (L3-L6) of Fe/SCATs. 


\section{ARTICLE}
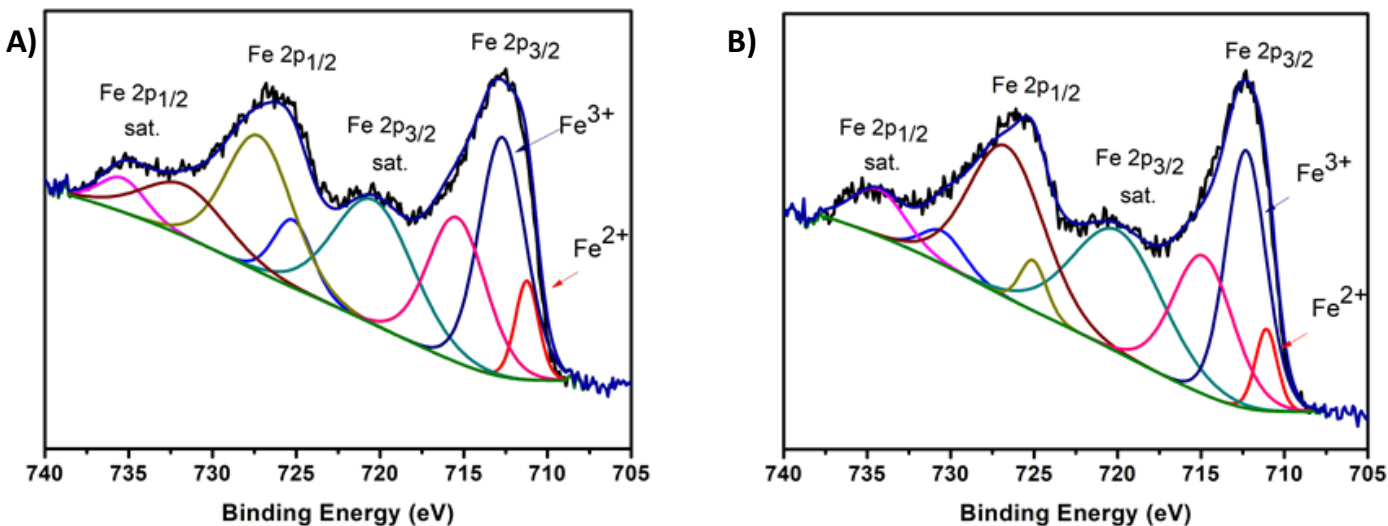

\begin{tabular}{|c|c|c|c|c|c|c|}
\hline \multirow{3}{*}{$\begin{array}{c}\text { Entry } \\
\text { Sample }\end{array}$} & \multicolumn{4}{|c|}{ Position / eV } & \multirow{2}{*}{\multicolumn{2}{|c|}{ Atomic / \% }} \\
\hline & \multicolumn{2}{|c|}{ Fe $2 p_{3 / 2}$} & \multicolumn{2}{|c|}{$\mathrm{Fe} 2 \mathrm{p}_{3 / 2}$ Sat. } & & \\
\hline & $\mathrm{Fe}(\mathrm{II})$ & Fe (III) & $\mathrm{Fe}$ (II) & $\mathrm{Fe}(\mathrm{III})$ & $\mathrm{Fe}(\mathrm{II})$ & $\mathrm{Fe}$ (III) \\
\hline Fe/SCATs & 711.2 & 712.7 & 715.4 & 720.4 & 17 & 83 \\
\hline Fe/SCATs after reaction & 711.1 & 712.3 & 714.9 & 720.0 & 14 & 86 \\
\hline
\end{tabular}

Fig. 5 XPS patterns and data of (A) Fe/SCATs before and (B) after reaction

The same laminar structure could also be visualised homogeneously covered by iron in Fe/SCATs (Fig.4-D and Fig.4E). With EDS analysis (Fig.4-C and Fig.4-H), selected surface areas (L1, L2 in Figure 1B, L3 in Fig.4-E and L5 in Fig.4-F) could be associated to $\mathrm{Pt}$ and $\mathrm{Ce}$ in both SCATs and Fe/SCATs, proving that the MW treatment did not influence the morphology of the supporting material. Other selected surface areas could be associate to Fe in sample Fe/SCATs (L4 in Fig.4-F and L6 in Fig.4$\mathrm{G})$. Homogenously distributed iron oxide nanoparticles of an average size of $2.4 \pm 0.4 \mathrm{~nm}$ with well-defined crystalline structure could be clearly observed in Fe/SCATs (Fig.4-I). No relevant changes were observed by STEM-HAADF and EDS of SCATs and Fe/SCATs after utilisation (please see Fig.S2 in the ESI for the STEM-HAADF images and EDS analysis).

XPS analysis (Fig.5) evidenced the presence of two intense peaks at binding energies of ca. $712.7 \mathrm{eV}$ and $726.3 \mathrm{eV}$, which confirmed the presence of an iron oxide phase, as reported by Moores et al. $^{34}$ The fitting of multiplets and satellites with highbinding energy could be assigned to iron oxide Fe (III) and the low-binding energy ones to $\mathrm{Fe}$ (II). ${ }^{40,41}$

\subsection{Selecting iron content in Fe/SCATs}

Firstly, the three different Fe/SCATs samples (called sample A, B and $C$, previously reported in Table 1 ) were tested in the one-pot cyclisation-hydrogenation of $( \pm)$-citronellal to menthols (analysing the diasteroisomers together) in order to select the most active catalyst, as illustrated in Scheme 2. For this purpose, only the $\mathrm{H}$-Cube Mini Plus was employed (as illustrated in Fig.S1-C in the ESI). The catalysts $(150 \mathrm{mg}$ ) were charged in a 30 $\mathrm{mm}$-long cartridge. The reactions were run using $20 \mathrm{mM}$ ( \pm )-citronellal in toluene, operating at $30 \mathrm{bar}_{2}$ pressure and at

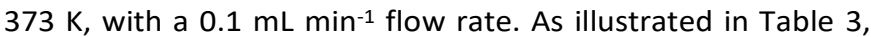
Entry 4, the best performance, specifically $~ 95 \%$ conversion of ( \pm )-citronellal with $\sim 53 \%$ selectivity to menthols and $\sim 40 \%$ selectivity to isopulegols, was achieved employing sample $A$, containing 7.5\% ${ }_{\mathrm{wt}} \mathrm{Fe}$.

As a result, sample A was selected for the following tests. Higher contents of iron were discharged due to the complexity in fixing the iron nanoparticles on the supporting material which would have had required much effort, not necessary against the high conversion already obtained (considering that iron nanoparticles catalyse only the cyclisation step).

Remarkably, Fe/SCATs were able to both catalyse the cyclisation of citronellal and the sequential hydrogenation of isopulegols (Table 3, Entries 2-4). SCATs also showed some activity (Table 3, Entry 1), but the low conversion of only $13 \%$ at $373 \mathrm{~K}$ demonstrated the need of two cartridges. 


\section{ARTICLE}

A)

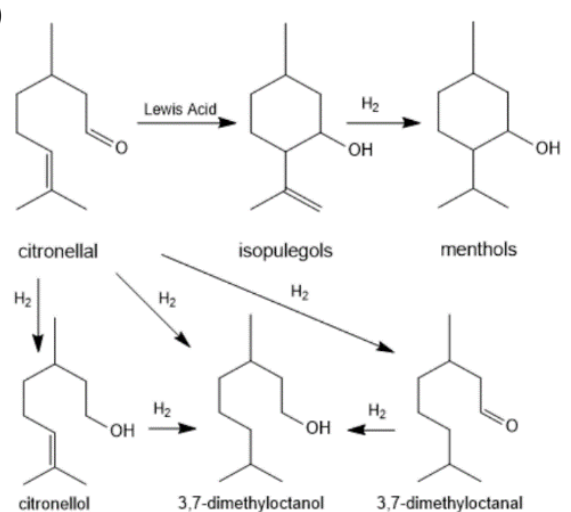

B)

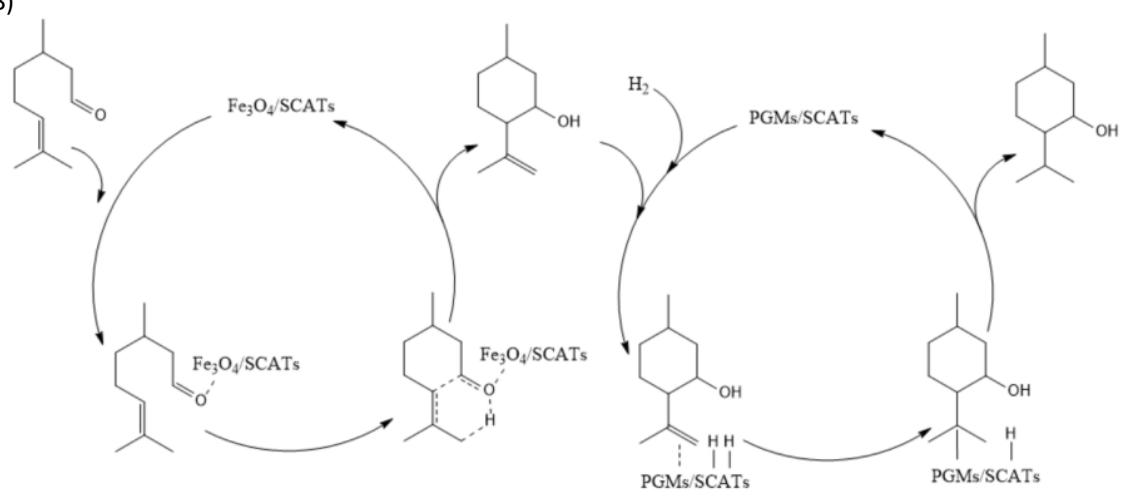

Scheme 2 Cyclisation of citronellal to isopulegols catalysed by Lewis acid and hydrogenation of isopulegols to menthols. A) Most relevant side products derive from the hydrogenation of citronellal. B) Proposed catalytic mechanism adapted from Sakamoto et al. ${ }^{42}$

Table 3 One-pot cyclisation-hydrogenation of ( \pm )-citronellal to menthols catalysed by Fe/SCATs.

\begin{tabular}{|c|c|c|c|c|c|c|c|c|}
\hline Entry & Sample & Conversion $\%^{[\mathrm{a}]}$ & $\mathrm{S}_{\text {isopulegols }} \%$ & $\mathrm{~S}_{\text {menthols }} \%$ & $\mathrm{~S}_{3,7 \text {-dimethyloctanol } \%}$ & $\mathrm{~S}_{3,7 \text {-dimethyloctanal } \%}$ & $\mathrm{~S}_{\text {citronellol }} \%$ & $Y_{\text {menthols } \%}$ \\
\hline 1 & SCATs & 9.6 & 38.5 & 9.6 & 39.4 & 0 & 12.4 & 0.9 \\
\hline 2 & C (1.8\% ${ }_{w t} F e$ /SCATs) & 66.2 & 60.2 & 36.0 & 0.8 & 1.6 & 1.5 & 23.8 \\
\hline 3 & $\mathrm{~B}\left(3.4 \%{ }_{\mathrm{wt}} \mathrm{Fe} / \mathrm{SCATS}\right)$ & 84.5 & 44.8 & 52.0 & 0.6 & 1.3 & 1.4 & 43.9 \\
\hline 4 & A (7.5\% ${ }_{w t} F e$ SCATs) & 94.4 & 40.0 & 56.1 & 1.3 & 1.6 & 1.0 & 52.9 \\
\hline
\end{tabular}

\subsection{Preliminary studies}

Sequentially, the tandem system was set up (please see Fig.S1-A and S1-B in the ESI). The reactions were run fixing Cartridge 1 (150 mg Fe/SCATs, $30 \mathrm{~mm}$-long cartridge) to the maximum operative temperature of the $\mathrm{H}$-Cube ${ }^{\circ}$ Mini Plus $(373 \mathrm{~K})$, while the temperature of Cartridge 2 (450 mg SCATs, $70 \mathrm{~mm}$-long cartridge) and the flow rate were varied. The reactions were carried out operating at 30 bar $\mathrm{H}_{2}$ pressure. As summarized in Fig.6, operating at a flow rate of $0.1 \mathrm{~mL} \mathrm{~min}^{-1}$, the conversion of citronellal improved from $74.8 \%$ up to $100 \%$ and the selectivity to menthols enhanced from $65.2 \%$ to $83.1 \%$ by only increasing the reaction temperature in Cartridge 2 (for a complete list of the trials please see Table S1, Entries 1-6 in the ESI). The best performance of $\sim 83 \%$ yield to menthols were obtained operating at $373 \mathrm{~K}$ in Cartridge 1 and $423 \mathrm{~K}$ in Cartridge 2. A higher $\mathrm{T}$ in Cartridge 2 was discharged as it gave almost the same yield to menthols.

A quick study varying the flow rate, confirmed that best operative conditions were obtained at $0.1 \mathrm{~mL} \mathrm{~min}^{-1}$ (please see Table S1, Entries 5,7 and 8 in the ESI).

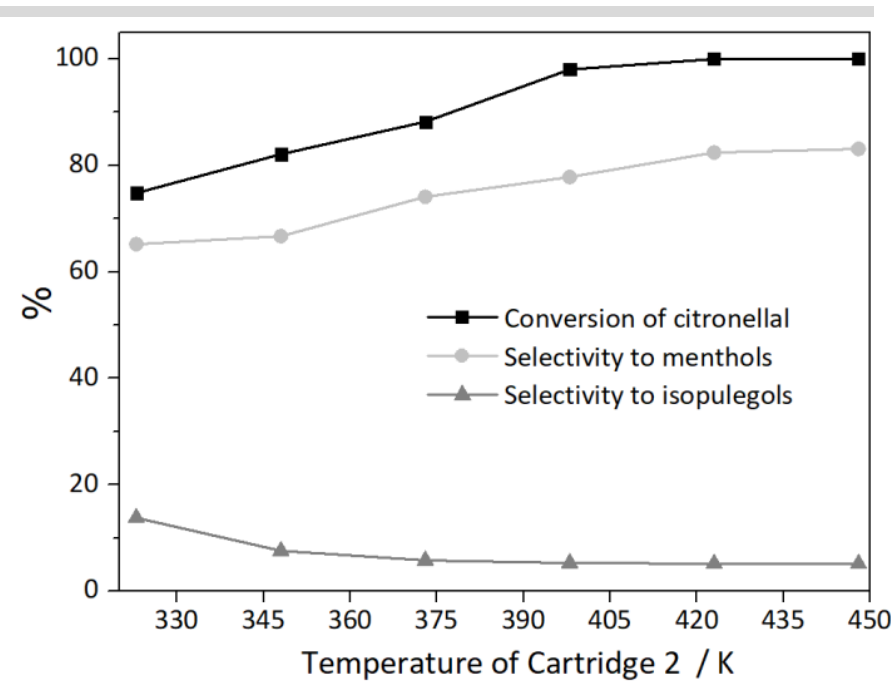

Fig.6 Performances of the tandem reaction carried out using 30 $\mathrm{mm}$-long Cartridge 1 and $70 \mathrm{~mm}$-long Cartridge 2. 


\subsection{Optimising the reaction}

In a second phase, in order to maximise the cyclisation step, a $70 \mathrm{~mm}$-long cartridge was employed as Cartridge 1 . The best operative conditions of the preliminary study were employed as starting parameters for the optimisation phase. The influence of the reaction parameters of $\mathrm{T}$ (of Cartridge 2), pressure and flow rate on ( \pm )-menthol yields were determined. As shown in Table 4, an improvement on the yields by increasing the temperatures could be observed, reaching a plateau at $413 \mathrm{~K}$ (Table 4, Entries 4-6). The results confirmed the data obtained in the preliminary study.

Table 4 Tandem cyclisation-hydrogenation of $( \pm)$-citronellal to ( \pm )--menthol. Reaction parameters: citronellal $20 \mathrm{mM}$ in toluene, $30 \mathrm{bar}_{2}$ pressure, $0.1 \mathrm{~mL}$ $\min ^{-1}$ flow rate.

\begin{tabular}{ccccc}
\hline Entry & $\mathrm{T}^{\mathrm{a}} / \mathrm{K}$ & $\mathrm{Y}_{\mathrm{ms}} / \%^{b}$ & $\mathrm{~S}_{( \pm)-\mathrm{m}} / \%$ & $\mathrm{Y}_{( \pm)-\mathrm{m}} / \%$ \\
\hline 1 & 348 & 76.7 & 81.1 & 62.2 \\
2 & 373 & 86.3 & 80.7 & 69.7 \\
3 & 398 & 87.6 & 79.7 & 69.8 \\
4 & 413 & 91.1 & 79.5 & 72.4 \\
5 & 423 & 89.8 & 80.6 & 72.4 \\
6 & 448 & 92.0 & 77.8 & 71.5 \\
\hline
\end{tabular}

a Temperature of Cartridge 1 fixed at $373 \mathrm{~K}$ - temperature of Cartridge 2 reported in the table. ${ }^{b}$ Yield $\%$ to menthols at stationary state.

Sequentially, the temperature of Cartridge 2 was set at $413 \mathrm{~K}$ (the minimum value of temperature of the plateau $Y_{( \pm)-m} v s T$ of Table 4, Entries 4-6) and the $\mathrm{H}_{2}$ pressure of the system was varied. The best performance was obtained working at 5 bar $\mathrm{H}_{2}$ pressure (Table 5 , entry 4 ).

$\mathrm{H}_{2}$ pressure was then set at 5 bar and the flow rate was subsequently optimized. As expected, a linear reduction in yields from $77.3 \%$ at $0.1 \mathrm{~mL} \mathrm{~min}^{-1}$ to $30.4 \%$ at $0.5 \mathrm{~mL} \mathrm{~min}^{-1}$ was noticed (please see ESI, Table S2, for the complete list of experiments).

A long-term stability analysis was eventually performed to demonstrate the stability of the tandem catalytic system under the investigated optimum reaction conditions (Fig. 7). Despite almost no changing in the yields to $( \pm)$-menthol in the first $7 \mathrm{~h}$ was noticed, a decrease of the yield to $( \pm$ )-menthol (down to $64.4 \%$ from an initial value of $75.6 \%$ ) was observed after $24 \mathrm{~h}$, and a plateau was noticed up to $72 \mathrm{~h}$ of reaction.

Table 5 Tandem cyclisation-hydrogenation of ( \pm )-citronellal to ( \pm )-menthol. Reaction parameters: citronellal $20 \mathrm{mM}$ in toluene, Cartridge 1 at $373 \mathrm{~K}$ Cartridge 2 at $413 \mathrm{~K}, 0.1 \mathrm{~mL} \mathrm{~min}^{-1}$ flow rate.

\begin{tabular}{ccccc}
\hline Entry & $\mathrm{H}_{2} \mathrm{p} /$ bar & $\mathrm{Y}_{\mathrm{ms}} / \%^{\mathrm{a}}$ & $\mathrm{S}_{( \pm)-\mathrm{m}} / \%^{\mathrm{b}}$ & $\mathrm{Y}_{( \pm)-\mathrm{m}} / \%^{\mathrm{c}}$ \\
\hline 1 & 30 & 91.1 & 79.5 & 72.4 \\
2 & 15 & 90.1 & 82.2 & 74.0 \\
3 & 10 & 90.4 & 82.9 & 74.9 \\
4 & 5 & 91.8 & 84.2 & 77.3 \\
5 & 2 & 89.4 & 80.9 & 72.4 \\
6 & 0 & - & - & - \\
\hline
\end{tabular}

${ }^{a}$ Yield \% to menthols at stationary state. ${ }^{b}$ Selectivity to ( \pm )-menthol. ${ }^{\mathrm{c}}$ Yield to ( \pm )-menthol.

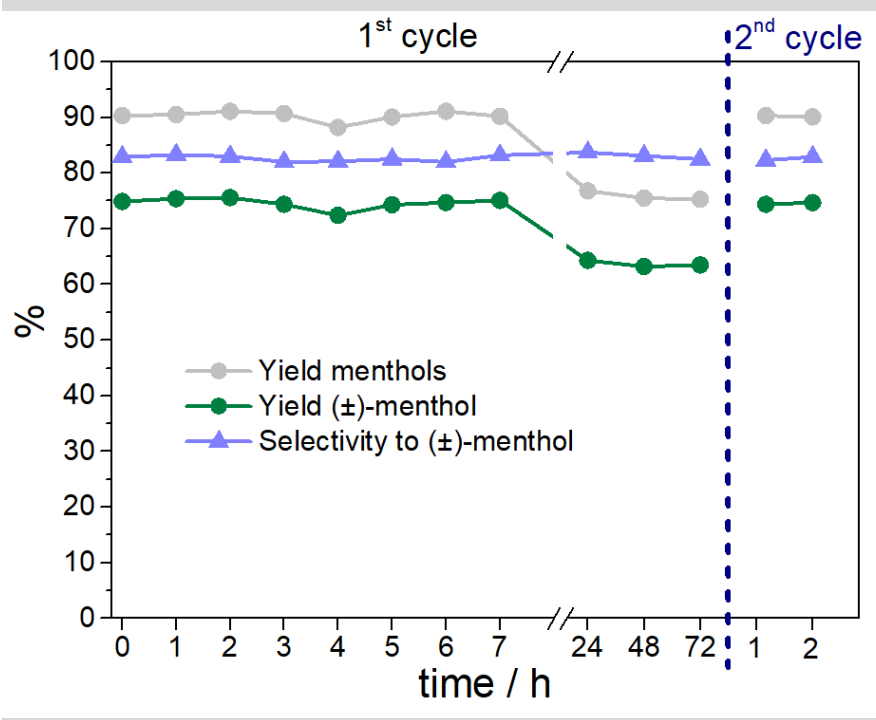

Fig.7 Selectivity and yields to ( \pm )-menthol in the tandem cyclisationhydrogenation of $( \pm)$-citronellal. Reaction parameters: citronellal 20 $\mathrm{mM}$ in toluene, Cartridge 1 at $373 \mathrm{~K}$; Cartridge 2 at $413 \mathrm{~K}, 0.1 \mathrm{~mL} \mathrm{~min}^{-1}$ flow rate, 5 bar $\mathrm{H}_{2}$ pressure. $2^{\text {nd }}$ cycle performed after washing the continuous flow apparatus with toluene for 20 '.

A washing cycle was subsequently performed by pumping toluene in the continuous flow apparatus in order to check if the reduction of the activity was due to adsorption of reactants/materials on the active surface of the catalysts rather than a deactivation. Almost identical yields were observed in the second cycle, most likely confirming that the slight drop in activity after $72 \mathrm{~h}$ could be due to adsorbed materials on the catalysts. ICP-MS analysis of the collected outcome liquid was also performed detecting no traces of iron or other metals, proving that no metal leaching occurred even under long term experiments. In order to confirm the efficiency of the proposed catalytic system, optimum reaction conditions were selected to produce (-)-menthol starting from enantiomerically pure $(+)$-citronellal. The final yield to (-)-menthol of $77.1 \%$ (side products include isomers of menthols) operating at $373 \mathrm{~K}$ (Cartridge 1, cyclisation step), $413 \mathrm{~K}$ (Cartridge 2, hydrogenation

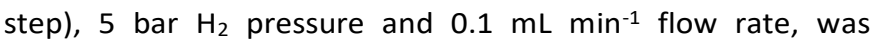
calculated by GC analysis on a chiral column and confirmed the versatility of the proposed system and the potential to extend the protocol to multiple tandem flow reactions. The menthols (having a high concentration of (-)-menthol) were sequentially isolated by distillation (in order to remove the solvent and low boiling substances) and chromatographic purification on a silica column. The optical rotation of the isolated menthols, derived from the optical rotation of $(-)$-menthol $\left([\alpha]^{20}{ }_{D}=-50\right)^{43}$ and its isomers, was measured to be $[\alpha]^{20}{ }_{D}=-38$.

In order to validate the proposed system in comparison with a conventional supporting material as well as with commercially available catalysts, the best reaction conditions were applied using $\mathrm{Fe} / \mathrm{SiO}_{2}$ and commercial $5 \%_{\mathrm{wt}} \mathrm{Pt} / \mathrm{C}$ and $5 \%_{\mathrm{wt}} \mathrm{Pd} / \mathrm{C}$ as catalysts, as illustrated in Table 6. 
Table 6 Tandem cyclisation-hydrogenation of ( \pm )-citronellal to ( \pm )-menthol. Reaction parameters: citronellal $20 \mathrm{mM}$ in toluene, Cartridge 1 at $373 \mathrm{~K}$. Cartridge 2 at $413 \mathrm{~K}, 0.1 \mathrm{~mL} \mathrm{~min}^{-1}$ flow rate, $5 \mathrm{bar} \mathrm{H}_{2}$ pressure.

\begin{tabular}{ccccc}
\hline Entry & Cartridge 1 & Cartridge 1 & $\begin{array}{c}\mathrm{Y}_{\mathrm{ms}} / \\
\%^{\mathrm{a}}\end{array}$ & $\mathrm{Y}_{( \pm)-\mathrm{m}} / \%^{\mathrm{b}}$ \\
\hline 1 & $\mathrm{Fe} / \mathrm{SCATs}(\mathrm{A})$ & SCATs & 91.8 & 77.3 \\
2 & $\mathrm{Fe} / \mathrm{SiO}_{2}(\mathrm{D})$ & SCATs & 86.4 & 70.2 \\
3 & $\mathrm{Fe} / \mathrm{SiO}_{2}(\mathrm{E})$ & SCATs & 69.1 & 50.4 \\
4 & $\mathrm{Fe} / \mathrm{SiO}_{2}$ (F) & SCATs & 61.4 & 40.3 \\
5 & $\mathrm{Fe} / \mathrm{SCATs}(\mathrm{A})$ & 5\%Pd/C & 88.1 & 70.3 \\
6 & $\mathrm{Fe} / \mathrm{SCATs}(\mathrm{A})$ & 5\%Pt/C & 88.9 & 82.3 \\
\hline
\end{tabular}

a Yield \% to menthols at stationary state. ${ }^{b}$ Yield to $( \pm)$-menthol.

Entries 2-4 demonstrated that the best performances were obtained using as iron precursor the mixture of Fe (II) and Fe (III) (that is the case of sample D, Entry 2). This behaviour was observed also by Moores et al. ${ }^{34}$ The slightly increased activity of Fe/SCATs (A) compared to sample $D$ (having same iron content but supported on $\mathrm{SiO}_{2}$ ), reported in Entry 1, can be explained in terms of higher stability of the iron nanoparticles over the smashed catalytic converters, as recently demonstrated by supporting Ru over SCATs. ${ }^{36}$ In addition, as reported in Table 3 Entry 1, SCATs itself showed some activity in the cyclization of citronellal to isopulegols, therefore increasing the final yield to menthols, where instead silica do not have catalytic activity.

\section{Conclusions}

In conclusion, a continuous flow tandem system for the synthesis of (-)-menthol starting from (+)-citronellal using low cost waste-derived catalysts was proposed for the first time. The efficiency of the instrumental set-up in both steps of the reaction was proved under different reaction conditions, highlighting the influence of flow parameters on the final yield to menthols. The catalytic system was also found to be highly robust as demonstrated in long-term stability tests, with no metal leaching nor changing in morphology or oxidation state of the metal. Under optimized conditions, (-)-menthol ( 77\% yield) could be produced from enantiomerically pure $(+)$-citronellal. The high versatility of the proposed system combined with its efficiency will pave the way to a number of additional chemistries under continuous flow conditions that will be reported in due course.

\section{Conflicts of interest}

The authors declare no conflicts of interest.

\section{Acknowledgements}

The authors thank Mr. Rafael Ángel Gómez Haro and Provaluta España Reciclaje de Metales, S.L., Córdoba (ES), for the supply of scrap automotive catalytic converters. Rafael Luque gratefully acknowledges MINECO for funding under project
CTQ2016-78289-P, co-financed with FEDER funds and the contract for Camilla Maria Cova associated to this project. This project has received funding from the European Union's Horizon 2020 research and innovation programme under the Marie Skłodowska-Curie grant agreement No 721290. This publication reflects only the author's view, exempting the Community from any liability. Project website: http://cosmicetn.eu/. HRSTEM studies were conducted at the Laboratorio de Microscopias Avanzadas, Instituto de Nanociencia de Aragon, Universidad de Zaragoza, Spain. The publication has been prepared with support from RUDN University program 5-100.

\section{References}

1 https://www.basf.com/us/en/media/science-around-us/thecool-freshness-of-menthol.html

2 G. P. P. Kamatou, I. Vermaak, A. M. Viljoen and B. M. Lawrence, Phytochem. 2013, 96, 15-25.

3 R. Eccles, J. Pharm. Pharmacol. 1994, 46, 618-630.

4 S. J. Anderson, Tob. Control 2011, 20, 1120-1128.

5 S. Kizil, N. Hasimi, V. Tolan, E. Kilinc and U. Yuksel, Turk. J. Field Crops 2010, 15, 148-153.

6 L. J. Macpherson, S. W. Hwang, T. Miyamoto, A. E. Dubin, A. Patapoutian and G. M. Story, Mol. Cell. Neurosci. 2006, 32, 335-343.

7 Y. H. Luo, W. P. Sun, X. J. Feng, X. Y. Ba, T. Liu, J. Guo, L. Z. Xiao, J. Jiang, Y. Hao, D. L. Xiong and C. Y. Jiang, Biochem. Bioph. Res. Co. 2019, 516, 825-830.

8 J. Hartner and U. M. Reinscheid, J. Mol. Struct. 2008, 872, 145 149.

9 J.C. Leffingwell and R.E. Shackelford, Cosmet. Perf. 1974, 89(6), 69-89.

10 R. Eccles, D. H. Griffiths, C. G. Newton and N. S. Tolley, Clin. Otolaryngol. 1988, 13, 25-29.

11 B. Etzold and A. Jess, Chem. Eng. Tachnol. 2008, 31, 12821289.

12 B. Etzold, A. Jess and M. Nobis, Catal. Today 2009, 140, 30-36.

13 A. Stolle, T. Gallert, C. Schmoeger and B. Ondruschka, RSC Adv. 2013, 3, 2112-2153.

14 M. Emura and H. Matsuda, Chem. Biodivers. 2014, 11, 16881699.

15 P. Kocovsky, G. Ahmed, J. Srogl, A. V. Malkov and J. Steele, J. Org. Chem. 1999, 64, 2765-2775.

16 T. Iwata, Y. Okeda, Y. Hori, US Patent 6774269 B2 2004, Takasago International Corporation.

17 S. Telalovic, A. Ramanathan, J. F. Ng, R. Maheswari, C. Kwakernaak, F. Soulimani, H. C. Brouwer, G. K. Chuah, B. M. Weckhuysen and U. Hanefeld, Chem-Eur. J. 2011, 17, 20772088.

18 P. R. S. Braga, A. A. Costa, E. F. de Freitas, R. O. Rocha, J. L. de Macedo, A. S. Araujo, J. A. Dias and S. C. L. Dias, J. Mol. Cat. AChem. 2012, 358, 99-105.

19 C. Milone, C. Gangemi, S. Minico, S. Galvagno and G. Neri, Chem. Indus. 1998, 75, 571-576.

20 Y. T. Nie, W. Niah, S. Jaenicke and G. K. Chuah, J. Catal. 2007, 248, 1-10.

21 F. Neatu, S. Coman, V. I. Parvulescu, G. Poncelet, D. De Vos and P. Jacobs, Top. Catal. 2009, 52, 1292-1300.

22 Y. T. Nie, S. Jaenicke and G. K. Chuah, Chem-Eur. J. 2009, 15, 1991-1999.

23 A. Negoi, S. Wuttke, E. Kemnitz, D. Macovei, V. I. Parvulescu, C. M. Teodorescu and S. M. Coman, Angew. Chem. Int. Ed. 2010, 49, 8134-8138.

24 J. Plosser, F. Dedeaga, M. Lucas and P. Claus, Appl. Catal. AGen. 2016, 516, 100-108. 
25 C. Moreno-Marrodan, F. Liguori, P. Barbaro, S. Caporali, L. Merlo and C. Oldani, Chemcatchem 2017, 9, 4256-4267.

26 J. ten Dam, A. Ramanathan, K. Djanashvili, F. Kapteijn and U. Hanefeld, RSC Adv. 2017, 7, 12041-12053.

27 G. Jas and A. Kirschning, Chem-Eur. J. 2003, 9, 5708-5723.

28 J. Wegner, S. Ceylan and A. Kirschning, Adv. Synth. Catal. 2012, 354, 17-57.

29 F. Gomollón-Bel, Chem. Int. 2019, 41, 12-16.

30 C. H. Kim, S. I. Woo and S. H. Jeon, Ind. Eng. Chem. Res. 2000, 39, 1185-1192.

$31 \mathrm{M}$. Zengin, H. Genc, T. Demirci, M. Arslan and $M$. Kucukislamoglu, Tetrahedron Lett. 2011, 52, 2333-2335.

32 E. Mieczynska, A. Gniewek and A. M. Trzeciak, Appl. Catal. AGen. 2012, 421, 148-153.

33 H. Genc, Catal. Commun. 2015, 67, 64-67.

34 A. Y. Li, M. Kaushik, C. J. Li and A. Moores, ACS Sustain. Chem. Eng. 2016, 4, 965-973.

35 J. Kaspar, P. Fornasiero and N. Hickey, Catal. Today 2003, 77 419-449.

36 C. M. Cova, A. Zuliani, M. J. Muñoz-Batista and R. Luque, Green Chem. 2019, 21, 4712-4722.

37 P. Gallezot and D. Richard, Catal. Rev. 1998, 40, 81-126.

38 A. Gutierrez, R. K. Kaila, M. L. Honkela, R. Slioor and A. O. I. Krause, Catal. Today 2009, 147, 239-246.

39 W. A. Bassett and D. M. Lapham, Am. Mineral. 1957, 42, 548555.

40 M. Omran, T. Fabritius, A. M. Elmandy, N. A. Abdel-Khalek, M El-Aref and A. Elmanawi, Appl. Surf. Sci. 2015, 345, 127-140.

41 I. Fanlo, F. Gervilla, E. Mateo and S. Irusta, EuEur. J. Mineral. 2008, 20, 125-129.

$42 \mathrm{H}$. Itoh, H. Maeda, S. Yamada, Y. Hori, T. Mino and M. Sakamoto, Org. Chem. Front., 2014, 1, 1107-1115.

43 F. Reinscheid and U. M. Reinscheid, J. Mol. Struct., 2016, 1103 166-176. 